\title{
Access to and availability of exercise facilities in Madrid: an equity perspective
}

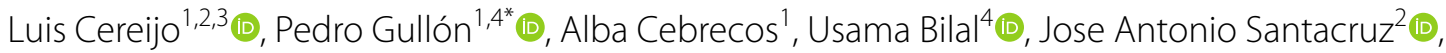 \\ Hannah Badland ${ }^{3}$ (i) and Manuel Franco ${ }^{1,5}$ (D)
}

\begin{abstract}
Background: Identifying socioeconomic determinants that are associated with access to and availability of exercise facilities is fundamental to supporting physical activity engagement in urban populations, which in turn, may reduce health inequities. This study analysed the relationship between area-level socioeconomic status (SES) and access to, and availability of, exercise facilities in Madrid, Spain.

Methods: Area-level SES was measured using a composite index based on seven sociodemographic indicators. Exercise facilities were geocoded using Google Maps and classified into four types: public, private, low-cost and sessional. Accessibility was operationalized as the street network distance to the nearest exercise facility from each of the 125,427 residential building entrances (i.e. portals) in Madrid. Availability was defined as the count of exercise facilities in a $1000 \mathrm{~m}$ street network buffer around each portal. We used a multilevel linear regression and a zero inflated Poisson regression analyses to assess the association between area-level SES and exercise facility accessibility and availability.
\end{abstract}

Results: Lower SES areas had a lower average distance to the closest facility, especially for public and low-cost facilities. Higher SES areas had higher availability of exercise facilities, especially for private and seasonal facilities.

Conclusion: Public and low-cost exercise facilities were more proximate in low SES areas, but the overall number of facilities was lower in these areas compared with higher SES areas. Increasing the number of exercise facilities in lower SES areas may be an intervention to improve health equity.

Keywords: Exercise, Socio-economic status, Exercise facilities, Inequities, Urban health

\section{Background}

Physical inactivity and sedentarism are major health concerns, as they are estimated to cause 3.2 million deaths globally annually, predominantly through chronic diseases, especially cardiovascular diseases [1-4]. Several studies have shown a social gradient in physical activity. For example, in Spain, those with the highest level of education also have the highest physical activity levels $(73.4 \%$ classified as sufficiently active), compared with those with medium or low education levels $(63.1 \%$ and $38.8 \%$ classified as sufficiently active, respectively) [5]. Moreover,

\footnotetext{
*Correspondence: pedro.gullon@edu.uah.es

1 Social and Cardiovascular Epidemiology Research Group, School of Medicine and Health Sciences, University of Alcalá, 28871 Alcalá de Henares, Madrid, Spain

Full list of author information is available at the end of the article
}

this social gradient represents a health equity issue in the prevalence of overweight and obesity in Madrid; residents that live in areas of lower SES have higher prevalence of obesity and overweight [6].

Population approaches [7] seek to change the distribution of risk factors within a population, through changing social determinants or environmental factors. An example of this is the neighbourhood built environment $[8,9]$. Systematic variation in the characteristics of the area of residence can contribute to disparities in physical activity [10]. For instance, access to physical activity resources may vary according to the sociodemographic characteristics of the neighbourhood, such as the predominant ethnic group, the median income level, deprivation or the ageing distribution [10-14]. These may contribute to some of the differences shown 
between physical activity accumulation and individuallevel socio-economic status [5].

Living closer to destinations that support physical activity (e.g. parks) has been associated with higher levels of physical activity [15-19]. In one hand, previous studies have showed how facility-rich environments encourage physical activity through the visual stimuli provided by the facilities presence and the numerous exercise models that they offer [20]. Secondly, it is usual that people report travel problems as a reason for quitting exercise programs [21]; living close to sport facilities reduces some psychological and physical barriers to exercise, such as travel time and traffic-related stress [20].

Evidence exists showing greater local access to sports facilities, such as gyms and sports fields, is independently associated with lower levels of adiposity [22]; other research has shown associations between the availability of exercise facilities and exercise [20]. Areas with a higher combined availability of local exercise facilities and parks have lower odds of obesity [23]. Moreover, activities supported through exercise facilities (e.g. gyms) tend to be structured and at moderate to vigorous intensity (MVPA) [24], which produces greater health benefits $[25,26]$. Moreover, the structured nature of the activities of this type of facilities make this activity more related with exercise. To wit, a physical activity that is planned, structured, repetitive, and purposive in the sense that improvement or maintenance of one or more components of physical fitness is an objective [27]. Despite this, relatively little research has examined the distribution of access to and availability of exercise facilities, such as gyms or swimming pools, by SES [22].

Previous studies show a clear social gradient in the practice of physical activity [28]. In low SES areas, where crime, or perceptions of crime, is often higher [29], exercise facilities play an important role in supporting health behaviours, as the streetscape and public open spaces may not be safe and aesthetically pleasing [30]. Identifying whether there are inequities in access and availability of exercise facilities by area-level disadvantage is an important step to informing urban planning policies that can improve population health through the pathway of physical activity engagement. While some studies have looked at perceptions of exercise facility availability and its relationship with physical activity, fewer studies have used objective indicators [31,32]. Of these studies, some lack a classification of facility types [22,33], and those that do have a classification, have not included variables that condition access, such us price, ownership or services, but instead utilise a general typology classification $[20,34]$. This is problematic because it does not allow us to know differentiated tendencies depending on the different types of facilities, specially between public and private facilities.

However, a gap in the exercise facility literature relates to the concepts of accessibility and availability. According to Penchansky and Thomas [35], accessibility incorporates the physical location of services in relation to individuals and resources required, such as transport and monetary or time costs to reach a service; meanwhile availability refers to the supply of health services, including the number and type of existing services [35]. Some studies define accessibility as the number of facilities available at a range of distances (buffers) around residents' homes [34] or by zip code [14]; others as the number of facilities available per 1000 population [36], or whether facilities were pay- or free-for-use [13]. We argue examining accessibility and availability simultaneously provides a more nuanced understanding of the exercise facility environment for a given region. Yet, to our knowledge, no research has examined both concepts of exercise facilities within the same study.

Building on these gaps in the evidence, the aim of the study was to investigate the associations between arealevel socioeconomic status with access to and availability of different types of exercise facilities and its spatial distribution using the case study of Madrid.

\section{Methods \\ Study setting}

The study is part of the Heart Healthy Hoods project, which broadly aims to study associations between the social and physical urban environment with cardiovascular health and inequity across Madrid, Spain [37].

This study was conducted across the municipality of Madrid, the capital of Spain. Madrid has a population of $3.2 \mathrm{M}$ residents and is divided into 21 districts that house 128 neighbourhoods. Within each neighborhood there are small geographical administrative units of $\sim 1500$ people each, called census sections $(\mathrm{N}=2415)$ [38]. Madrid's socio-spatial configuration is one of the most segregated in Europe [39].

\section{Exposure: area-level socioeconomic status}

The main exposure used in this study was a composite area-level socioeconomic status index created using seven socioeconomic status indicators: (1) low education; (2) high education; (3) part-time employment; (4) temporary employment; (5) manual occupational class; (6) average housing prices (per $\mathrm{m}^{2}$ ); and (7) unemployment rate. These indicators were selected based on the four domains present in the Spanish Commission to Reduce Health Inequalities [40] (education, wealth, occupation and living conditions). Occupation and living conditions indicators were assessed at 
the neighbourhood level. The area-level disadvantage index was calculated for each census section of the study area. The index has been used in other research [41], and further details regarding index construction are described in Additional file 1. For the purposes of this paper, the index was collapsed into deciles, where $1=$ most disadvantaged census sections and $10=$ least disadvantaged census sections.

\section{Outcomes: exercise facilities}

Exercise facilities were defined as indoor exercise facilities, both public and private, which offered physical activity programs, both with monthly subscription or pay per session (e.g. fitness clubs, sport centres, dance clubs, Pilates studios). Informal facilities (e.g. public parks or outdoor playing fields), cycling paths, private clubs (e.g. exercise facilities not accessible to the public, schools, or private sport clubs) were excluded.

Exercise facility information was collected by 'MAS Servicios Integrales' between April and October of 2015. All exercise facilities across Madrid were identified by Google Maps. Information about the programs and services were sourced through telephone and faceto-face interviews with facility managers. All facilities were visited physically to check the information collected. Data collection was carried out by four trained observers. Quality assurance was carried out by repeating the above process again in two districts using different trained data collectors.

The database used in this study comprised of 595 exercise facilities with five variables on facility characteristics. These were: (1) Name of the facility; (2) Address; (3) Monthly price; (4) Type of sports programs and services offered; (5) Ownership (public vs private). The exercise facilities were further classified into four exercise facility 'types', as described in Table 1. Similar classifications have been used in previous studies [14, 34].

\section{Portal}

We identified all residential building entrances in the city from CARTOCIUDAD [42] by identifying all external access identifiers located in a residential land use (total $\mathrm{n}$ of 125,440 . We exclude entrances whose nearest facility was located more than $6 \mathrm{~km}$ away $(\mathrm{N}=13)$, as these entrances were located in the edge of the city of Madrid, and their closest exercise facility might not be in the city in Madrid, but in a surrounding small region. All the spatial measures were calculated using ArcGIS 10.1 software.

\section{Measure of accessibility to exercise facilities}

We calculated the distance from each portal (origin) to the nearest exercise facility (destination) using a street network analysis; this better represents the true spatial distance between points when compared with a Euclidean distance [43]. We calculated the distance to "any" exercise facility less than $6 \mathrm{~km}$, and the distance to the nearest facility of each type (Table 1 ).

\section{Measure of availability of exercise facilities}

We calculated the availability (count) of exercise facilities in total and by type using a $1000 \mathrm{~m}$ street network buffer. There is empirical evidence suggesting $1000 \mathrm{~m}$ is the distance people are most likely to walk to fulfil daily activities [43]. In fact, previous studies showed that $1000 \mathrm{~m}$ from home to an exercise facility is the distance with the highest correlation with moderate to vigorous physical activity [44], and this distance has previously been applied in exercise facility research $[22,44,45]$.

\section{Mapping of spatial distribution}

Two cartographic maps were developed to facilitate the visualization of the spatial distribution of exercise facilities in terms of accessibility and availability. Those maps were made from the calculation of the average distance to the nearest exercise facility (accessibility) and number

Table 1 Descriptive analysis of the exercise facilities about accessibility and availability

\begin{tabular}{|c|c|c|c|c|c|c|c|c|}
\hline \multirow[t]{2}{*}{ Exercise facility type } & \multirow[t]{2}{*}{ Definition } & \multirow[t]{2}{*}{$N$} & \multicolumn{3}{|l|}{ Accessibility } & \multicolumn{3}{|c|}{ Availability } \\
\hline & & & Median (m) & IQR & & $\begin{array}{l}\text { Median } \\
\text { (count) }\end{array}$ & IQR & \\
\hline All the facilities & & 595 & 369.89 & 222.94 & 603.89 & 5 & 2 & 9 \\
\hline Publicly owned & Monthly payment option. Public ownership & 59 & 1058.35 & 713.39 & 1466.25 & 0 & 0 & 1 \\
\hline Privately owned & Monthly payment $\geq 30 € /$ month. Private ownership & 222 & 611.42 & 353.53 & 1042.11 & 2 & 0 & 4 \\
\hline Low cost & Monthly payment $<30 € /$ month. Private ownership & 63 & 1092.23 & 666.42 & 1791.08 & 0 & 0 & 1 \\
\hline Sessional & $\begin{array}{l}\text { Facilities with Pay-per-session (e.g. Pilates Studios, Dance } \\
\text { Schools, electrostimulation centres...). Private ownership }\end{array}$ & 251 & 594.35 & 328.49 & 1036.33 & 2 & 0 & 4 \\
\hline
\end{tabular}


of exercise facilities $1000 \mathrm{~m}$ around (availability) of each census section.

\section{Statistical analyses}

To study the association between accessibility to the nearest exercise facility and area-level SES we used linear mixed models with log transformed distance as the dependent variable and the SES index as the independent variable. This was a three-level model with a random intercept for neighbourhood and for census section. We included the independent variable (SES Index) operationalized as deciles, with the first decile (lowest SES) as the reference, group. To study the relationship between availability of exercise facilities and area-level SES, we used a Zero Inflated Poisson (ZIP) model. We chose a ZIP model instead of a mixed effects Poisson due to the high number of 0's in the distribution of the dependent variable. We estimated robust standard errors clustered by census section to take into account the intra-census section correlation. We ran all models for all facilities and stratified by type of facility. All analyses were conducted using Stata/SE 14.1 for Mac (StataCorp., College Station, TX, USA).

\section{Results}

Overall, the median distance to the nearest exercise facility (any type) from each portal was $364 \mathrm{~m}$ $(\mathrm{IQR}=220 \mathrm{~m}-596 \mathrm{~m})$. By type, low-cost facilities were furthest away (median distance $=1090 \mathrm{~m}$, $\mathrm{IQR}=663 \mathrm{~m}-1789 \mathrm{~m})$, and sessional facilities were most proximate (median distance $=596 \mathrm{~m}, \mathrm{IQR}=331 \mathrm{~m}$; $1035 \mathrm{~m}$ ) (Table 1).

All portals had two or more exercise facilities of any type located within $1000 \mathrm{~m}$, and half of the portals had at least five facilities available at this distance. However, half of the portals had neither public exercise facilities nor low cost facilities available within $1000 \mathrm{~m}$. Private and sessional facilities had the highest availability, with at least two exercise facilities available within $1000 \mathrm{~m}$ for half the portals.

\section{Exercise facility accessibility and SES}

Overall, there was a social gradient in public, private and sessional facilities, where portals in low SES areas have better accessibility to the nearest exercise facility compared with higher SES areas (Fig. 1b-d). However, this association differed by type of facility. Areas with lower SES had higher accessibility to public exercise facilities (Fig. 1b). Similar patterns, though less strong, were observed for privately owned facilities (Fig. 1c) and lowcost facilities (Fig. 1d). In the case of sessional facilities, this gradient was unclear. Despite this, portals in the lowest SES areas (decile 1) had the lowest accessibility to the nearest exercise facility. This was shown for all types of exercise facilities when compared with the next leastdeprived SES decile.

The spatial distribution of area-level SES and average distance to the nearest exercise facilities by type is shown in Fig. 2. The portals of the down-town area of Madrid (inside the M-30 orbital motorway of Madrid) show shorter distances to exercise facilities. Public exercise facilities are more accessible in the southern areas of the city when compared with the north, meanwhile the sessional exercise facilities show the opposite relationship. Low-cost and private exercise facilities were located most proximally in the downtown and southeastern areas. Private exercise facilities were located most proximally in the southwestern region.
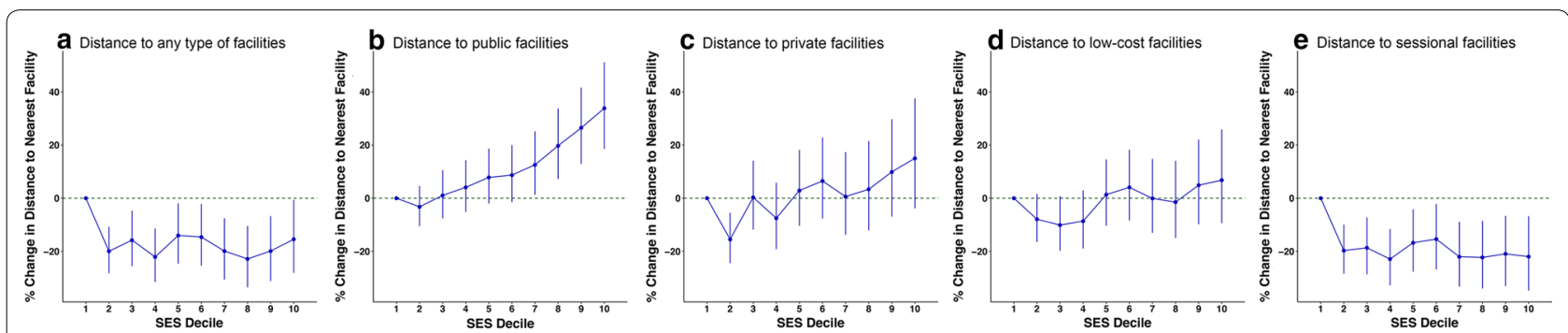

Fig. 1 Area-level SES and accessibility to nearest exercise facility. Note Distance=logarithm of distance to nearest facility; SES= socio-economic status 

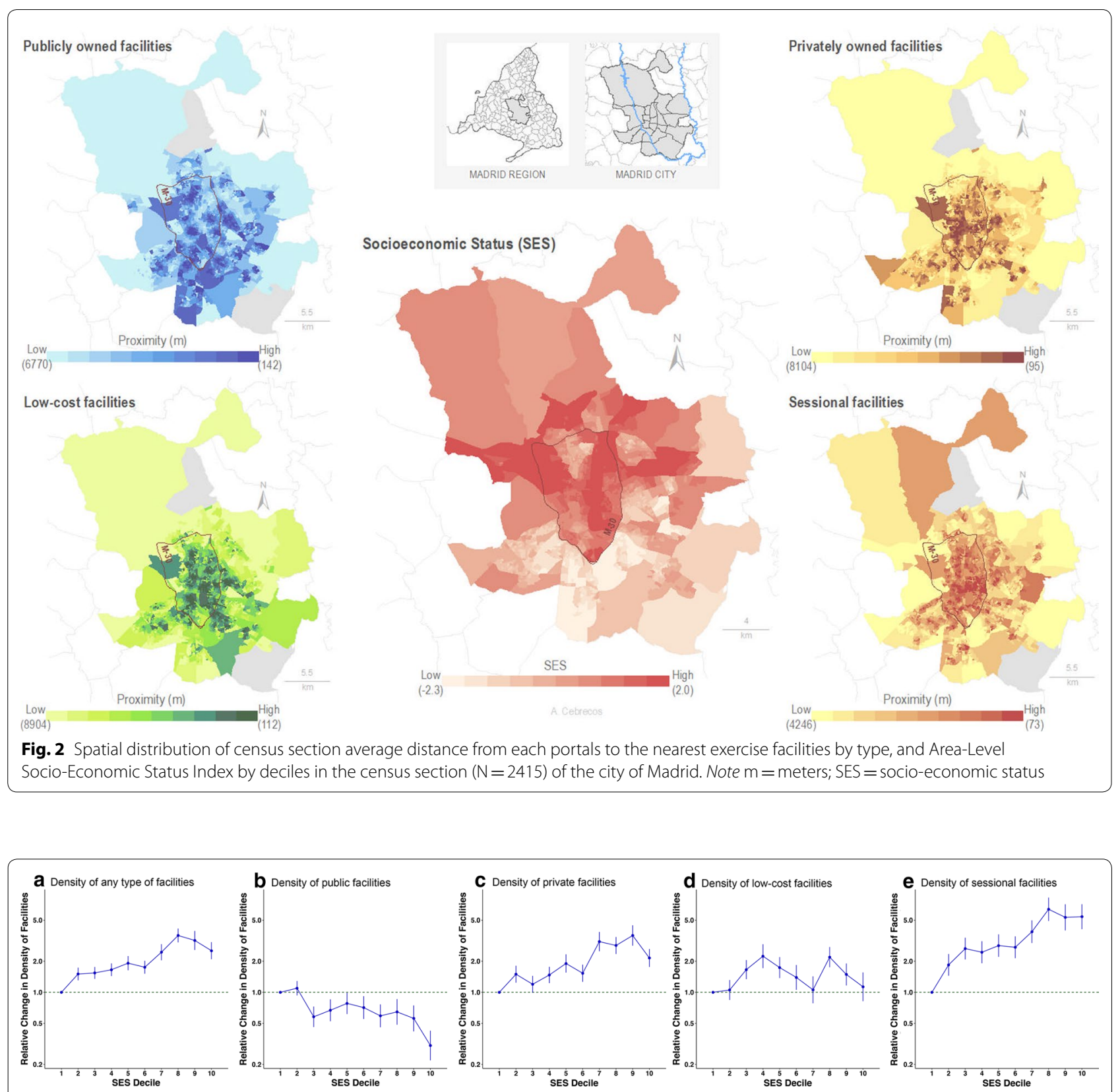

Fig. 3 Area-level SES and availability of exercise facilities. Note IRR = incidence rate ratio; SES= socio-economic status

\section{Exercise facility availability and SES}

There is a reverse social gradient in the association to availability of exercise facilities (Fig. 3), as there is a higher density of facilities in higher SES areas. The strongest associations with availability were shown for private and sessional exercise facilities, with the number of facilities increasing in areas of higher SES. This patterning was not present when public or low cost exercise facilities were considered.
Figure 4 shows differences in the spatial distribution of the availability of exercise facility types between the downtown area of Madrid and the periphery of the city. Downtown and northern areas (high SES) have greater availability of all types of exercise facilities. Public facilities have a higher level of availability when compared with other facility types, especially in the southern part of the city. Private and low-cost facilities have higher availability in the lower SES areas of the south than sessional facilities, which are more present in the higher SES areas of the north. 


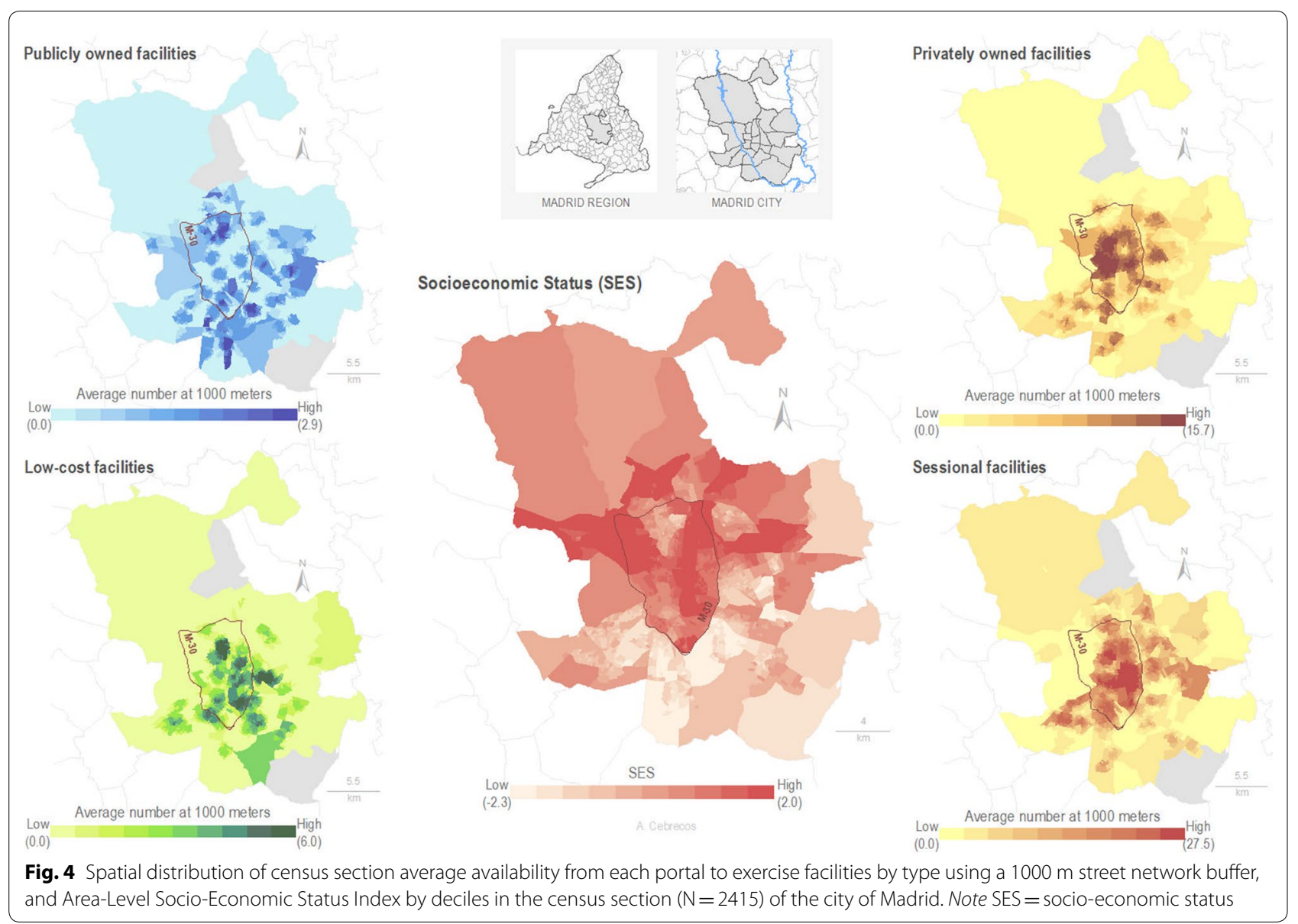

\section{Discussion}

This study showed that, while people in Madrid living in low SES areas had better access to exercise facilities, residents in higher SES areas had greater availability of exercise facilities. The relationship between accessibility and area-level SES varied depending on the type of exercise facility, yet all types (except sessional facilities) presented a social gradient where distances generally tended to be more proximal in low SES areas. This gradient was most strong for the publicly owned and low-cost facilities. The availability analysis showed an increased likelihood of having more than one facility available as area-level SES increased. This pattern was clearest with private and sessional facility types. Our paper builds on this novelty research by further classifying exercise facilities into types, collecting primary data, and examining the socio-spatial patterning of exercise facilities by access and availability.

Our results are consistent with previous research that showed a negative association between area-level SES and proximity, in terms of distance, to recreational facilities [46-48], green spaces [47, 49,50], and playgrounds
[51, 52]. However, other studies have shown a greater proximity of green spaces for high SES areas, but not for other facilities [53-55]. This suggests that exercise facilities accessibility could act as a barrier of social disadvantaged, as an "advantage in the disadvantaged $[41,56]$.

Our availability results are consistent with previous studies that demonstrated higher density of facilities in areas of higher SES $[13,14,34,57]$. Other studies, developed in different countries, found that there are more facilities in lower-SES areas $[58,59]$, while others have reported mixed or null results [60]. A previous study carried out in Madrid with older adults and secondary data sources showed similar availability of exercise facilities to those of our study. It concluded that reduced availability of exercise facilities in disadvantaged populations was a contributor to physical inactivity in older adults [36].

While the low SES areas had better accessibility and lower availability of exercise facilities, the higher SES areas presented opposite relationships. This could be explained by a high concentration of exercise facilities in the centre of Madrid, where census sections tended to have higher SES; on the other hand, the neighbourhoods 
on the periphery of the city (lower SES, especially in the south) have a more dispersed distribution of exercise facilities.

\section{Strengths and limitations}

This is the first multilevel study that: (1) analysed exercise facilities, in terms of accessibility and availability, and examined this in relation to area-level disadvantage; and (2) classified and examined exercise facilities based on price, subscription type and ownership.

The results show the importance of doing research that incorporates both access and availability measures simultaneously, and when combined with SES, can reveal different (and sometimes opposite) social-spatial patterning and social gradients. Examining the different types of exercise facilities yielded diverse results when considered by area-level SES, particularly in relation to generating a better understanding of the (in)equities of delivery. Another strength was the use of primary data for exercise facilities and accessibility and availability measures in Madrid. Finally, using the whole municipality of Madrid provided a high level of population variation to examine the socio-spatial distribution of exercise facilities.

Some limitations of this study should be highlighted. This research did not take into account the impact of the accessibility and availability of exercise facilities with behaviours of the population, such as facility use or physical activity engagement. There have also been concerns that area-level SES measures may not be suitable proxies for individuallevel SES because of potential disagreement between contextual and compositional effects [61]. Because of the absence of individual data, portals were used to estimate accessibility and availability of exercise facilities from the residences of the Madrid population; however, exercise facilities around workplaces and/or study centers, may also be important but were not investigated. Finally, our focus was exercise facilities, therefore, we might have missed other physical activity destinations, such as playgrounds or parks. However, we chose to restrict to study exercise facilities since the activities supported in exercise facilities (e.g. gyms) tend to be more structured and include moderate to vigorous intensities (MVPA) [24], which produces greater health benefits $[25,26]$.

\section{Policy recommendations}

Presence of exercise facilities have a great importance on the physical activity engagement of the populations. Not only for the type of the structured activities provided [24], but also for the impact on the neighbourhood environment [20].

In one hand, previous studies have pointed how the facility-rich environment encourage physical activity through the visual stimuli provided by the own facilities and the numerous role models presence thanks to the nearby facilities [20]. Secondly, is usual that people report inconvenience and travel problems as reasons for quitting of exercise programs [21]; to live near facilities reduce some psychological and physical barriers to exercise, such as travel time and traffic-related stress [20].

Previous studies have reported a positive relationship between the availability of exercise facilities and moderate to vigorous physical activity [62] and a negative relationship with adiposity [22]. Therefore, the low availability of exercise facilities detected in areas with low SES brings a double disadvantaged scenario for those populations, such as in the southern districts of Villaverde and Puente de Vallecas, as well as some areas in the southeast part of the city.

An increase of opportunities for physical activity in more disadvantaged areas, either through subsidy systems of private facilities or increasing the availability of public facilities, could produce an upturn in the aggregate demand of physical activity. This planned growth should focus on low fixed price or no cost facilities, as those with a variable price (such as sessional) are negatively related to participation in physical activity [63], and may be a barrier for those who are disadvantaged people.

\section{Research agenda}

Future studies should try to extend our findings using individual-level behavioural data to better understand how exercise environment is associated with facility use and physical activity engagement. In future, a wider range of internal characteristics of the facilities should be assessed (e.g. service quality, cultural appropriateness, timetabling), alongside understanding how these attributes are associated with facility use. Also, a qualitative approach to evaluate the characteristics of exercise facilities could improve our understanding of the barriers/enablers people face when selecting (or not) exercise facilities to attend, and whether this differs by SES.

\section{Conclusions}

Our findings showed that associations between accessibility and availability of exercise facilities with area-level SES varied depending on facility type. Areas with lower SES demonstrated better accessibility in general to exercise facilities, whereas higher SES areas had greater facility availability, especially when privates and sessional types were considered.

Relatively little research to date has examined exercise facilities, when compared with evidence focussing on other physical activity locations, such us parks or neighbourhoods. This study makes an important contribution to knowledge about the socio-spatial delivery of exercise facilities in our cities. 


\section{Additional file}

Additional file 1. Area Level Socioeconomic status indicators.

\section{Abbreviations}

SES: socio-economic status; MVPA: moderate to vigorous physical activity.

\section{Acknowledgements}

The authors would like to thank MAS Servicios Integrales for facilitating the access to their data on exercise facilities, and to the Heart Healthy Hoods team for the support. We also would like to thank to Prof. David Valadés PhD, for his advice and support during the development of the present study.

\section{Authors' contributions}

LC, PG and MF conceived the idea. UB developed the area-level socioeconomic status index. JAS and LC collected and clean the database of exercise facilities. LC and PG carried out the statistical analysis. AC carried out the spatial analysis and the cartography. LC drafted the manuscript. All authors provided critical intellectual contributions. All authors read and approved the final manuscript.

\section{Funding}

This study forms part of the Heart Healthy Hoods, project funded by the European Research Council under the European Union's Seventh Framework Programme (FP7/2007-2013/ERC Starting Grant Heart Healthy Hoods Agreement No. 336893). PG was supported by the 2018 Alfonso Martín Escudero Research Grant. HB is supported by an RMIT University Vice Chancellor's Senior Research Fellowship and is the Australian Health Promotion Association Thinker in Residence. UB was supported by the Office of the Director of the National Institutes of Health under Award Number DP5OD26429.

\section{Availability of data and materials}

The data that support the findings of this study are available from MAS Servicios Integrales but restrictions apply to the availability of these data, which were used under license for the current study, and so are not publicly available. Data are however available from the authors upon reasonable request and with permission of MAS Servicios Integrales.

\section{Ethics approval and consent to participate}

We conducted this study in accordance with the Declaration of Helsinki, and received ethical approval by the Madrid Primary Care Research Committee. There were no human subjects involved in the study.

\section{Consent for publication}

Not applicable.

\section{Competing interests}

The authors declare that they have no competing interests.

\section{Author details}

${ }^{1}$ Social and Cardiovascular Epidemiology Research Group, School of Medicine and Health Sciences, University of Alcalá, 28871 Alcalá de Henares, Madrid, Spain. ${ }^{2}$ Management and Sports Training Research Group, School of Medicine and Health Sciences, University of Alcalá, 28871 Alcalá de Henares, Madrid, Spain. ${ }^{3}$ Centre for Urban Research, RMIT University, Melbourne, Australia. ${ }^{4}$ Urban Health Collaborative, Drexel Dornsife School of Public Health, Philadelphia, PA, USA. ${ }^{5}$ Department of Epidemiology, Johns Hopkins Bloomberg School of Public Health, Baltimore, MD, USA.

Received: 25 March 2019 Accepted: 24 June 2019 Published online: 02 July 2019

\section{References}

1. Global status report on noncommunicable diseases 2014 [Internet]. Geneva: World Health Organization; 2014. https://apps.who.int/iris/bitst ream/handle/10665/148114/9789241564854_eng.pdf.
2. Chau JY, van der Ploeg HP, Merom D, Chey T, Bauman AE. Cross-sectional associations between occupational and leisure-time sitting, physical activity and obesity in working adults. Prev Med (Baltim). 2012;54:195200. https://doi.org/10.1016/j.ypmed.2011.12.020.

3. Booth FW, Roberts CK, Laye MJ. Lack of exercise is a major cause of chronic diseases. Compr Physiol. 2012;2:1143-211.

4. Unick J, Lang W, Tate D, Bond D, Espeland M. Objective estimates of physical activity and sedentary time among young adults. J Obes. 2017. https ://doi.org/10.1155/2017/9257564.

5. Encuesta de hábitos deportivos en España [Internet]. Madrid: Consejo Superior de Deportes. Ministerio de Educación Cultura y Deporte. Gobierno de España; 2015. http://www.culturaydeporte.gob.es/servicios-alciudadano/estadisticas/deportes/encuesta-habitos-deportivos-en-espan a.html.

6. Estudio de Salud de la ciudad de Madrid 2018 [Internet]. Madrid: Madrid Salud, Ayuntamientio de Madrid; 2019. http://madridsalud.es/wp-conte nt/uploads/2019/01/AVANCE-ESTUDIO-SALUD-21-ENERO-2019.pdf.

7. Rose G. Sick individuals and sick populations. Int J Epidemiol. 1985;14:32-8

8. Franco M, Bilal U, Diez-Roux AV. Preventing non-communicable diseases through structural changes in urban environments. J Epidemiol Community Health. 2014;69:509-11. https://doi.org/10.1136/jech-2014-20386 5.

9. Bauman AE, Reis RS, Sallis JF, Wells JC, Loos RJF, Martin BW, et al. Physical activity 2 correlates of physical activity: why are some people physically active and others not? Lancet. 2012;380:258-71. https://doi.org/10.1016/ S0140-6736(12)60735-1.

10. Wylie BJ, Singh MP, Coull BA, Quinn A, Yeboah- K, Sabin L, et al. Disparities in physical activity resource availability in six US regions. Prev Med (Baltim). 2015;34:355-68.

11. Abercrombie LC, Sallis JF, Conway TL, Frank LD, Saelens BE, Chapman JE. Income and racial disparities in access to public parks and private recreation facilities. Am J Prev Med. 2008;34:9-15.

12. Cohen DA, Lapham S, Evenson KR, Williamson S, Golinelli D, Ward P, et al. Use of neighbourhood parks: does socio-economic status matter? A four-city study. Public Health. 2013;127:325-32. https://doi.org/10.1016/j. puhe.2013.01.003.

13. Estabrooks PA, Lee RE, Gyurcsik NC. Resources for physical activity participation: does availability and accessibility differ by neighborhood socioeconomic status? Ann Behav Med. 2003;25:100-4. https://doi. org/10.1207/S15324796ABM2502_05.

14. Powell LM, Slater S, Chaloupka FJ, Harper D. Availability of physical activity-related facilities and neighborhood demographic and socioeconomic characteristics: a national study. Am J Public Health. 2006;96:1676-80.

15. Coombes $E$, Jones AP, Hillsdon M. The relationship of physical activity and overweight to objectively measured green space accessibility and use. Soc Sci Med. 2010;70:816-22. https://doi.org/10.1016/j.socsc imed.2009.11.020.

16. Coutts C, Chapin T, Horner M, Taylor C. County-level effects of green space access on physical activity accessibility of green space. J Phys Act Health. 2013;10:232-40.

17. Gordon-Larsen P, Nelson MC, Page P, Popkin BM. Activity and obesity inequality in the built environment underlies key health disparities in physical inequality in the built environment underlies key health disparities in physical activity and obesity. Pediatrics. 2006;117:417-24. https:// doi.org/10.1542/peds.2005-0058.

18. Hanibuchi T, Kawachi I, Nakaya T, Hirai H, Kondo K. Neighborhood built environment and physical activity of Japanese older adults: results from the Aichi Gerontological Evaluation Study (AGES). BMC Public Health. 2011;11:657. https://doi.org/10.1186/1471-2458-11-657.

19. Van Cauwenberg J, Nathan A, Barnett A, Barnett DW, Cerin E, Council on Environment and Physical Activity (CEPA)-Older Adults Working Group. Relationships between neighbourhood physical environmental attributes and older adults' leisure-time physical activity: a systematic review and meta-analysis. Sport Med. 2018;48:1635-60. https://doi.org/10.1007/ s40279-018-0917-1.

20. Sallis JF, Hovell MF, Hofstetter CR, Elder JP, Hackley M, Caspersen CJ, et al. Distance between homes and exercise facilities related to frequency of exercise among San Diego residents. Public Health Rep. 1990;105:179-85. 
21. Andrew GM, Oldridge NB, Parker JO, Cunningham DA, Rechnitzer PA, Jones $\mathrm{NL}$, et al. Reasons for dropout from exercise programs in postcoronary patients. Med Sci Sports Exerc. 1981;13:164-8.

22. Mason KE, Pearce N, Cummins S. Associations between fast food and physical activity environments and adiposity in mid-life: cross-sectional, observational evidence from UK Biobank. Lancet Public Health. 2018;3:e16-23. https://doi.org/10.1016/S2468-2667(17)30212-8.

23. Hobbs M, Griffiths C, Green MA, Jordan H, Saunders J, McKenna J. Associations between the combined physical activity environment, socioeconomic status, and obesity: a cross-sectional study. Perspect Public Health. 2018;138(3):169-72. https://doi.org/10.1177/1757913917748353.

24. Ainsworth BE, Haskell WL, Whitt MC, Irwin ML, Swartz AM, Strath SJ, et al. Compendium of physical activities: an update of activity codes and MET intensities. Med Sci Sport Exerc. 2000;32(Supplement):S498-516. https:// doi.org/10.1097/00005768-200009001-00009.

25. Blair SN, Cheng Y, Scott Holder J. Is physical activity or physical fitness more important in defining health benefits? Med Sci Sports Exerc. 2001;33(Supplement):S379-99. https://doi.org/10.1097/00005768-20010 6001-00007.

26. Lear SA, Hu W, Rangarajan S, Gasevic D, Leong D, labal R, et al. The effect of physical activity on mortality and cardiovascular disease in 130,000 people from 17 high-income, middle-income, and low-income countries: the PURE study. Lancet. 2017;390:2643-54. https://doi.org/10.1016/S0140 $-6736(17) 31634-3$

27. Caspersen CJ, Powell KECG. Physical activity, exercise and physical fitness: definitions and distinctions for health related research. Public Health Rep. 1985;100:126-31.

28. Beenackers MA, Kamphuis CBM, Giskes K, Brug J, Kunst AE, Burdorf A, et al. Socioeconomic inequalities in occupational, leisure-time, and transport related physical activity among European adults: a systematic review. Int J Behav Nutr Phys Act. 2012;9:116.

29. Foster S, Giles-Corti B. The built environment, neighborhood crime and constrained physical activity: an exploration of inconsistent findings. Prev Med (Baltim). 2008;47:241-51.

30. Ball K, Salmon J, Giles-corti B, Crawford D. How can socio-economic differences in physical activity among women be explained? A qualitative study. Women Health. 2006;43:93-113. https://doi.org/10.1300/J013V 43n01_06.

31. Rütten $A$, Abel T, Kannas L, Von Lengerke T, Lüschen $G$, Rodriguez Diaz JA, et al. Self reported physical activity, public health, and perceived environment: results from a comparative European study. J Epidemiol Community Health. 2001;55:139-46.

32. Humpreys B. Economic determinants of participation in physical activity and sport. Working Paper Series International Association of Sports Economists. 2006;4410, August: 06-13.

33. Ellaway A, Lamb KE, Ferguson NS, Ogilvie D. Associations between access to recreational physical activity facilities and body mass index in Scottish adults. BMC Public Health. 2016;16:1-9. https://doi.org/10.1186/s1288 9-016-3444-8

34. Hillsdon M, Panter J, Foster $C$, Jones A. Equitable access to exercise facilities. Am J Prev Med. 2007;32:506-8.

35. Penchansky R, Thomas JW. The concept of access definition and relationship to consumer satisfaction. Med Care. 2015;19:127-40.

36. Pascual C, Regidor E, Álvarez-del Arco D, Alejos B, Santos JM, Calle ME, et al. Sports facilities in Madrid explain the relationship between neighbourhood economic context and physical inactivity in older people, but not in younger adults: a case study. J Epidemiol Community Health. 2013;67:788-94. https://doi.org/10.1136/jech-2013-202583.

37. Franco M. Heart Healthy Hoods Project: http://www.hhhproject.eu. Starting Grant 2013 European Research Council. 2013. http://www.hhhproject .eu.

38. INE. Estadísticas del padrón continuo 2014. Madrid, 2014. 2014.

39. Leal J, Sorando D. Economic crisis, social change and segregation processes in Madrid. In: Tammaru T, Marcińczak S, van Ham M, Musterd S, editors. Socio-Economic Segregation in European Capital Cities. East meets West. London (UK): Routledge; 2015. p. 214-337.

40. Avanzando hacia la equidad. Propuesta de políticas e intervenciones para reducir las desigualdades sociales en salud en España [Internet]. Madrid: Ministerio de Sanidad Servicios Sociales e Igualdad. Gobierno de España; 2015, p. 17-23. https://www.mscbs.gob.es/profesionales/saludPublica/
prevPromocion/promocion/desigualdadSalud/docs/Propuesta_Polit icas_Reducir_Desigualdades.pdf

41. Gullon P, Bilal U, Cebrecos A, Badland HM, Galan I, Franco M. Intersection of neighborhood dynamics and socioeconomic status in small-area walkability: the Heart Healthy Hoods project. Int J Health Geogr. 2017;16:21. https://doi.org/10.1186/s12942-017-0095-7.

42. Instituto Geográfico Nacional. CARTOCIUDAD Project. 2014. http://www. cartociudad.es. Accessed 1 Sept 2017.

43. Koohsari MJ, Mavoa S, Villianueva K, Sugiyama T, Badland H, Kaczynski AT, et al. Public open space, physical activity, urban design and public health: concepts, methods and research agenda. Health Place. 2015;33:75-82. https://doi.org/10.1016/j.healthplace.2015.02.009.

44. Eriksson U, Arvidsson D, Sundquist K. Availability of exercise facilities and physical activity in 2,037 adults: cross-sectional results from the Swedish neighborhood and physical activity (SNAP) study. BMC Public Health. 2012;12:1. https://doi.org/10.1186/1471-2458-12-607.

45. Kaufman TK, Rundle A, Neckerman KM, Sheehan DM, Lovasi GS, Hirsch JA. Neighborhood recreation facilities and facility membership are jointly associated with objectively measured physical activity. J Urban Health. 2019. https://doi.org/10.1007/s11524-019-00357-1.

46. Giles-Corti B, Donovan RJ. Socioeconomic status differences in recreational physical activity levels and real and perceived access to a supportive physical environment. Prev Med (Baltim). 2002;35:601-11.

47. Mavoa S, Koohsari MJ, Badland HM, Davern M, Feng X, Astell-Burt T, et al. Area-level disparities of public open space: a geographic information systems analysis in metropolitan melbourne. Urban Policy Res. 2015;33:306-23.

48. Pearce J, Witten K, Hiscock R, Blakely T. Are socially disadvantaged neighbourhoods deprived of health-related community resources? Int J Epidemiol. 2007;36:348-55.

49. Kessel A, Green J, Pinder R, Wilkinson P, Grundy C, Lachowycz K. Multidisciplinary research in public health: a case study of research on access to green space. Public Health. 2009;123:32-8. https://doi.org/10.1016/j. puhe.2008.08.005.

50. Hobbs M, Green MA, Griffiths C, Jordan H, Saunders J, Grimmer H, et al. Access and quality of parks and associations with obesity: a cross-sectional study. SSM Popul Health. 2017;3:722-9.

51. Smoyer-Tomic KE, Hewko JN, Hodgson MJ. Spatial accessibility and equity of playgrounds in Edmonton, Canada. Can Geogr. 2004;48:287-302.

52. Cradock AL, Kawachi I, Colditz GA, Hannon C, Melly SJ, Wiecha JL, et al. Playground safety and access in Boston neighborhoods. Am J Prev Med. 2005;28:357-63.

53. Rigolon A, Flohr T. Access to parks for youth as an environmental justice issue: access inequalities and possible solutions. Buildings. 2014;4:69-94.

54. Harris CD, Paul P, Zhang X, Fulton JE. Park access among School-Age Youth in the United States. J Phys Act Health. 2015;12(6 Suppl 1):S94-101.

55. Wen M, Zhang X, Harris CD, Holt JB, Croft JB. Spatial disparities in the distribution of parks and green spaces in the USA. Ann Behav Med. 2013:45(Suppl. 1):2304-12.

56. King KE, Clarke PJ. A disadvantaged advantage in walkability: findings from socioeconomic and geographical analysis of national built environment data in the United States. Am J Epidemiol. 2015;181:17-25.

57. Macintyre S. The social patterning of exercise behaviours: the role of personal and local resources. Br J Sports Med. 2000;34:6. https://doi. org/10.1136/bjsm.34.1.6.

58. Ogilvie D, Lamb KE, Ferguson NS, Ellaway A. Recreational physical activity facilities within walking and cycling distance: sociospatial patterning of access in Scotland. Health Place. 2011;17:1015-22. https://doi. org/10.1016/j.healthplace.2011.07.003.

59. Weyers S, Diehl K, Gruber J, D’Agostino A, Schneider S. Neighborhood deprivation and physical activity facilities - no support for the deprivation amplification hypothesis. J Phys Act Health. 2014;12:990-7.

60. Jacobs J, Alston L, Needham C, Backholer K, Strugnell C, Allender S, et al. Variation in the physical activity environment according to area-level socio-economic position-a systematic review. Obes Rev. 2018;2019:115. https://doi.org/10.1111/obr.12818.

61. Pardo-Crespo MR, Narla NP, Williams AR, Beebe TJ, Sloan J, Yawn BP, et al. Comparison of individual-level versus area-level socioeconomic measures in assessing health outcomes of children in Olmsted County, Minnesota. J Epidemiol Community Health. 2013;67:305-10. 
62. Wang L, Tang Y, Luo J. School and community physical activity characteristics and moderate-to-vigorous physical activity among Chinese school-aged children: a multilevel path model analysis. J Sport Health Sci. 2017;6:416-22. https://doi.org/10.1016/j.jshs.2017.09.001.

63. Anokye NK, Pokhrel S, Buxton M, Fox-Rushby J. The demand for sports and exercise: results from an illustrative survey. Eur J Health Econ. 2012;13:277-87

\section{Publisher's Note}

Springer Nature remains neutral with regard to jurisdictional claims in published maps and institutional affiliations.
Ready to submit your research? Choose BMC and benefit from:

- fast, convenient online submission

- thorough peer review by experienced researchers in your field

- rapid publication on acceptance

- support for research data, including large and complex data types

- gold Open Access which fosters wider collaboration and increased citations

- maximum visibility for your research: over $100 \mathrm{M}$ website views per year

At BMC, research is always in progress.

Learn more biomedcentral.com/submissions 